\title{
Ablation in the left ventricle in a patient with electrical storm and two mitral valve clips.
}

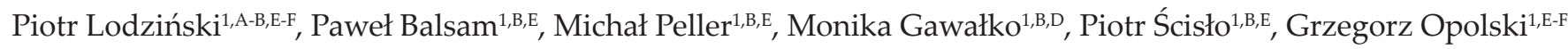 \\ A - Research concept and design, B - Collection and/or assembly of data, C - Data analysis and interpretation, \\ D - Writing the article, E - Critical revision of the article, F - Final approval of article \\ 1. I Katedra i Klinika Kardiologii Warszawski Uniwersytet Medyczny
}

Address for correspondence:

Piotr Lodziński, I Katedra i Klinika Kardiologii Warszawski Uniwersytet Medyczny email: piotr.lodzinski@wum.edu.pl

Paweł Balsam, I Katedra i Klinika Kardiologii Warszawski Uniwersytet Medyczny email: pawel.balsam@wum.edu.pl

Michał Peller, I Katedra i Klinika Kardiologii Warszawski Uniwersytet Medyczny email: michalpeller@gmail.com

Monika Gawałko, I Katedra i Klinika Kardiologii Warszawski Uniwersytet Medyczny email: mongawalko@gmail.com

Piotr Ścisło, I Katedra i Klinika Kardiologii Warszawski Uniwersytet Medyczny email: scislo@wum.edu.pl

Grzegorz Opolski, I Katedra i Klinika Kardiologii Warszawski Uniwersytet Medyczny email: grzegorz.opolski@wum.edu.pl

Received: 2018-12-21

Revised:

Accepted: 2018-12-21

Final review: 2018-12-21

DOI: $10.24255 / \mathrm{hbj} / 102280$

\section{Key words:}

ventricular tachycardia, electrical storm, mitral clips, radiofrequency ablation, heart failure

\section{Abstract}

Coexistence of ventricular tachyarrhythmias and mitral valve regurgitation is frequently observed in elderly patients. The antegrade-transseptal approach to treat left ventricular tachyarrhythmia is useful and widespread. However, data on the antegrade approach for mapping and ablating left ventricular tachyarrhythmia in patients after mitral valve

\section{INTRODUCTION}

Coexistence of ventricular tachyarrhythmias and mitral valve regurgitation (MR) is frequently observed in elderly patients with advanced ischemic or dilated cardiomyopathy ${ }^{[1]}$. Transcatheter mitral valve repair using the MitraClip has become a common approach to treat significant MR, especially in patients deemed inoperable or having high surgical risk $^{[2]}$. The most effective method of restoring a potentially life-threatening rhythm such as ventricular tachycardia (VT) or ventricular fibrillation (VF) is catheter ablation (CA). So far, repair with the MitraClip are insufficient. We present a case of a 74-year-old patient referred to our department diagnosed with electrical storm and successfully treated with catheter ablation using the anterograde transmitral catheter route just six months after implantation of two MitraClips.

evidence-based management of CA performed through the mitral valve with MitraClips is very limited. There are only a few reports of such cases, most of them presenting CA at least one year after MitraClip implantation ${ }^{[3,4]}$. We present the case of a patient with electrical storm successfully treated with CA just six months after implantation of two MitraClips.

\section{CASE REPORT}

A 74-year-old man was referred to our department for CA for acute treatment of electrical storm. At admission, there 
were 31 adequate high energy implantable cardioverter-defibrillator (ICD) interventions. Six months earlier, the patient underwent transcatheter mitral valve repair with implantation of two MitraClips. Moreover, he had a history of non-ischemic dilated cardiomyopathy, a cardiac resynchronization therapy defibrillator (CRT-D) implanted for primary prevention (left ventricle ejection fraction $23 \%$ ), paroxysmal atrial fibrillation, hypertension, chronic renal failure and chronic obstructive pulmonary disease.

The preprocedure echocardiogram revealed left ventricle enlargement (left ventricular end-diastolic diameter $7 \mathrm{~cm}$; end-diastolic volume $228 \mathrm{ml}$; end-systolic volume $175 \mathrm{ml}$ ). During the electrophysiology study, hemodynamically unstable VT was easily induced by programmed ventricular stimulation (cycle length $270 \mathrm{~ms}$ ). Left ventricular electro-anatomical mapping seen in Figure 1 was performed using

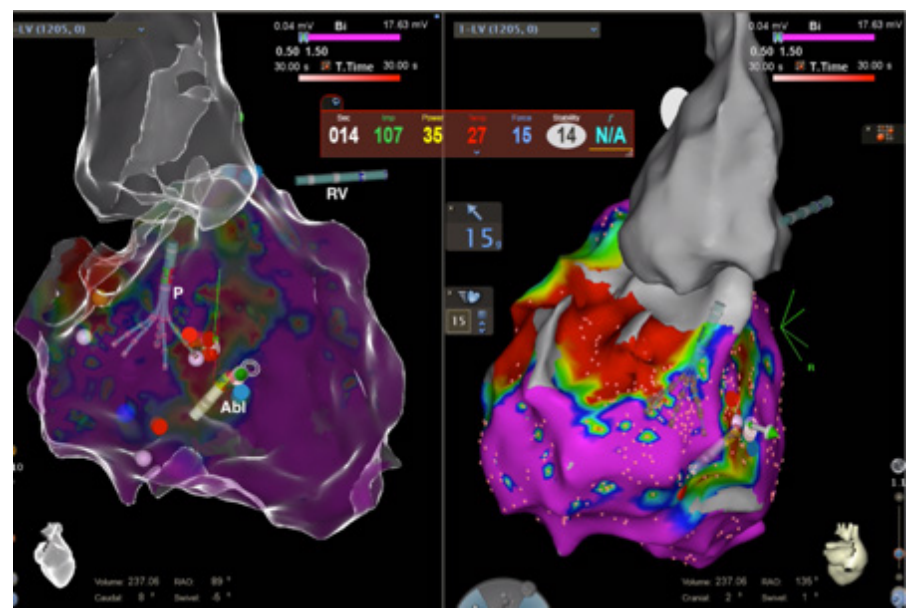

Figure 1.3D map of left ventricle during ablation procedure Abl - cooled tip ablation catheter with force feedback inserted through steerable transseptal sheath and through the mitral valve (transseptal approach); P - multipolar diagnostic catheter (transaortic approach).

the CARTO system (Biosense Webster, Diamond Bar, CA, USA) and multipolar diagnostic catheter (PentaRay, Biosense Webster). The access to the left ventricle was obtained by the retrograde and the antegrade approach. For the antegrade approach, venous access was obtained via the right femoral vein. Following transseptal puncture under echocardiographic and fluoroscopic guidance (Figure 2), one steerable sheath (Agilis, Abbott) was advanced to the left atrium and crossed the mitral valve with the MitraClip devices. For the retrograde approach, one long sheath (Swartz SL0, Abbot) was inserted via the right femoral artery. CA in the area characterized by low-amplitude and long-lasting fragmented potential (intraventricular septum) was performed with a bidirectional steerable catheter with a 3.5-mm open-irrigated tip (NaviStar Smart SF; Biosense Webster). Acute success was defined as non-inducibility of any VT using the same protocol that was used before ablation with up to three extrastimuli. After the procedure, the patient underwent two-dimensional transthoracic echocardiography, which revealed no mitral valve regurgitation progression and stable position of MitraClips. During 3 and 6 months of observation, there were no VT episodes in the ICD memory.

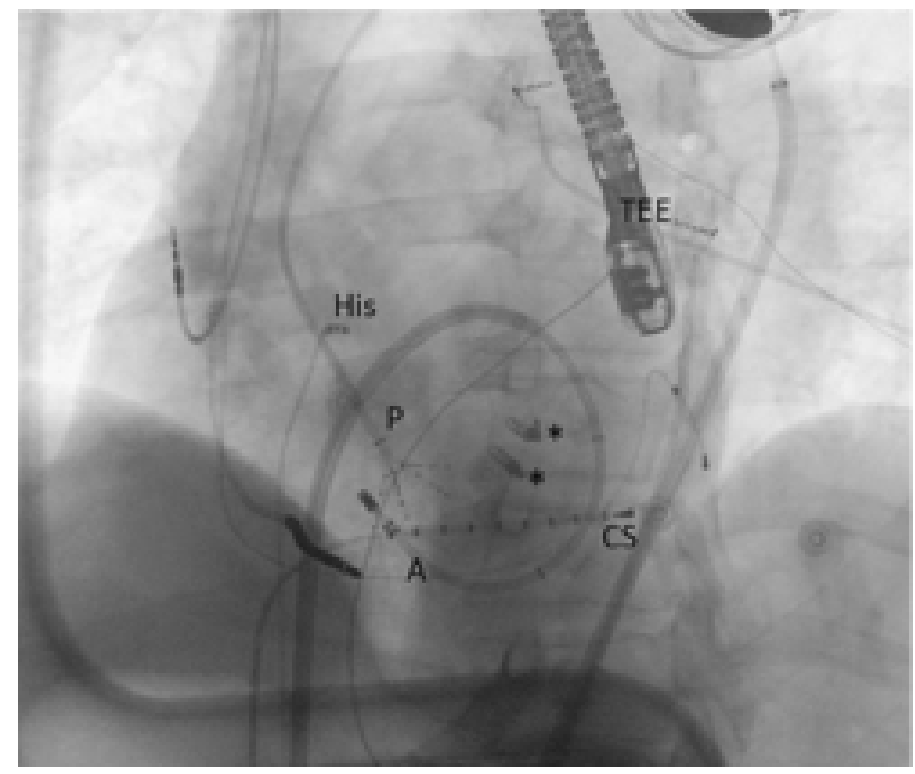

Figure 2. Fluoroscopic image during ablation procedure TEE - transesophageal echo probe; His - His bundle diagnostic catheter, CS - coronary sinus diagnostic catheter, ${ }^{*}$ - clips on mitral valve; $A$ - cooled tip ablation catheter with force feedback inserted through steerable transseptal sheath and through the mitral valve (transseptal approach); P - multipolar diagnostic catheter (transaortic approach).

\section{DISSCUSION}

This case report provides data on the safety and feasibility of using CA of an electronic storm in a patient with an implanted MitraClip. The presence of the two implanted MitraClip devices did not preclude safe transmitral catheter access after transseptal puncture, especially when large steerable sheaths and multipolar mapping catheters were used.

As mentioned by previous publications, the antegrade approach of left ventricle tachyarrhythmia ablation would be safe to perform at 6 months after MitraClip implantation. It can be explained by the healing response after device implantation that encompassed four phases: acute ( $\leq 30$ days), subacute (31 to 90 days), chronic (91 to 300 days), and long term ( $>300$ days). The chronic healing response characterized by various degrees of tissue bridging between the device arms adds structural stability ${ }^{[5]}$. Severe adhesions of the MitraClip to the mitral valve might be observed even at approximately 180 days after implantation ${ }^{[3]}$. Therefore, a careful procedure is required, and, according to the experience of Haegeli et al., performing CA under direct TEE guidance is crucial to avoid mitral valve trauma ${ }^{[4]}$.

Recent studies proved that the antegrade approach provides good contact and stability to mid-anteroseptal sites (as in our case) during $\mathrm{CA}^{[3,6]}$. Tilz et al. compared the antegrade and retrograde left ventricle mapping approaches in terms of impact on contact force and catheter stability. Median antegrade and retrograde contact forces were $16.0 \mathrm{~g}$ and 15.3 $\mathrm{g}$, respectively. The contact force was significantly higher antegradely in mid-anteroseptal, mid-lateral and apical segments compared to the retrograde approach in basal segments ${ }^{[6]}$. With a transseptal route, $41 \%$ of the mapping points displayed a contact force $>20$ g versus $30 \%$ with a retroaortic approach ${ }^{[7]}$. Mizuno et al. reported a mean contact force during left ventricle endocardium mapping of $10.5 \pm 9.2 \mathrm{~g}$ using a retroaortic 
approach alone, whereas, by combining it with the transseptal approach, the CF significantly increased to $13.9 \pm 10.2 \mathrm{~g}^{[8]}$.

The antegrade approach is not always necessary to achieve left ventricle ablation ${ }^{[3,9]}$. However, it can be a better option, especially for patients who have undergone mechanical aortic valve replacement, those who have severe peripheral vascular disease, or those with a left ventricle assist device.

As shown in our case and earlier reports, the antegrade approach of left ventricle tachyarrhythmia ablation in patients with previous MitraClip implantation is safe. However, in such patients, we underscore the need for special attention during the ablation procedure using TEE guidance.

\section{References}

1. Olafiranye O, Hochreiter CA, Borer JS, et al. Nonischemic mitral regurgitation: prognostic value of nonsustained ventricular tachycardia after mitral valve surgery. Cardiology 2013;124:108-115.

2. Feldman T, Kar S, Elmariah S, et al. Randomized comparison of percutaneous repair and surgery for mitral regurgitation: 5-year results of EVEREST II. J Am Coll Cardiol 2015;66:2844-2854.

3. Hayashi K, Heeger $\mathrm{CH}$, Mathew S, et al. Antegrade-transseptal approach for left ventricular tachyarrhythmia in patients with previous Mitraclip implantation. Europace. 2018;20: 1527-1534.

4. Haegeli LM, D'Angelo G, Trevisi N, et al. Catheter ablation of ventricular tachycardia in patients with MitraClip device: preliminary findings. J Cardiovasc Electrophysiol 2017;28: 523-530.

5. Ladich E, Michaels MB, Jones RM, et al. Pathological healing response of explanted MitraClip devices. Circulation 2011;123:1418-27.

6. Tilz RR, Makimoto H, Lin T, et al. In vivo left-ventricular contact force analysis: comparison of antegrade transseptal with retrograde transaortic mapping strategies and correlation of impedance and electrical amplitude with contact force. Europace 2014;16:1387-1395.

7. Jesel L, Sacher F, Komatsu Y, et al. Characterization of contact force during endocardial and epicardial ventricular mapping. Circ Arrhythm Electrophysiol 2014;7:1168-1173.

8. Mizuno H, Vergara P, Maccabelli G, et al. Contact force monitoring for cardiac mapping in patients with ventricular tachycardia. J Cardiovasc Electrophysiol 2013;24:519-524.

9. Sacher F, Reichlin T, Zado ES, et al. Characteristics of ventricular tachycardia ablation in patients with continuous flow left ventricular assist devices. Circ Arrhythm Electrophysiol 2015;8:592-597. 